\title{
The Neurocognition of Referential Ambiguity in Language Comprehension
}

Mante S. Nieuwland*

Tufts University and MGHIMIT/HMS Athinoula A. Martinos Center for Biomedical Imaging

\author{
Jos J. A. Van Berkum \\ Max Planck Institute for Psycholinguistics and F. C. Donders Centre for Cognitive \\ Neuroimaging
}

\begin{abstract}
Referential ambiguity arises whenever readers or listeners are unable to select a unique referent for a linguistic expression out of multiple candidates. In the current article, we review a series of neurocognitive experiments from our laboratory that examine the neural correlates of referential ambiguity, and that employ the brain signature of referential ambiguity to derive functional properties of the language comprehension system. The results of our experiments converge to show that referential ambiguity resolution involves making an inference to evaluate the referential candidates. These inferences only take place when both referential candidates are, at least initially, equally plausible antecedents. Whether comprehenders make these anaphoric inferences is strongly context dependent and co-determined by characteristics of the reader. In addition, readers appear to disregard referential ambiguity when the competing candidates are each semantically incoherent, suggesting that, under certain circumstances, semantic analysis can proceed even when referential analysis has not yielded a unique antecedent. Finally, results from a functional neuroimaging study suggest that whereas the neural systems that deal with referential ambiguity partially overlap with those that deal with referential failure, they show an inverse coupling with the neural systems associated with semantic processing, possibly reflecting the relative contributions of semantic and episodic processing to re-establish semantic and referential coherence, respectively.
\end{abstract}

\section{Introduction}

According to Herodotus, when the powerful king Croesus of Lydia asked the Delphi oracle whether he should go to war with the Persians, the answer he got was 'If you attack the Persians, you will destroy a mighty kingdom.' For those acquainted with the infamy of oracles in Greek mythology, the ambiguity in this oracular reply may present itself immediately: 'a mighty kingdom' could be taken to refer to the kingdom of the Persians, but also 
to that of Croesus himself (or perhaps even some other kingdom). The Delphian ambiguity illustrates that language comprehenders have to fulfil at least two important tasks in order to arrive at a contextually appropriate interpretation for a given word. Aside from establishing its general lexical meaning, they also to determine to what or whom it refers.

The current paper deals with the situation when comprehenders are temporarily unable to establish referential meaning, because a word has multiple potential referential candidates (i.e. referential ambiguity). In an event-related brain potential (ERP) study, Van Berkum et al. (1999) brought referential ambiguity out under the radar of neurocognitive investigation by showing its distinctive impact on neural processing. Below, we will touch upon the notion of referential meaning and discuss the role of referential ambiguity in natural language and in psycholinguistic experimentation, before reviewing a series of neurocognitive experiments on this topic from our laboratory.

\section{REFERENTIAL MEANING}

The notion of referential meaning is often traced back to Frege (1892; reprinted in Martinich 1990) who, in order to resolve a philosophical debate at that time, distinguished two types of meaning ('sense' and 'reference', or 'Sinn und Bedeutung'; though similar distinctions had already been made by other theorists; see Martinich 1990). For Frege, reference was the object in the world that a word refers to, whereas sense was whatever cognitive significance a word has when there is no specific object to be referred to. The most famous demonstration of this distinction goes like this: the expressions 'the morning star' and 'the evening star' have different senses, as the former is the first bright object (other than the sun or moon) to appear in the eastern sky at sunrise, and the latter is the last to disappear in the western sky at sunset. But they have the same reference as they refer to the same object, the planet Venus (before this fact was discovered, people thought they were observing two different celestial bodies). Stating that 'the morning star $=$ the morning star' is trivial and uninformative, but stating that 'the morning star $=$ the evening star' provides significant information about the world. Thus, the ultimate meaning of a statement is determined by a combination of the sense and reference of its terms.

For Frege, reference involved the relationship between linguistic expressions and entities in the real world. In contemporary psycholinguistics, however, establishing referential meaning (also known as 'anaphoric processing') generally pertains to the identity relationships between linguistic expressions and entities 'in the real world as modelled in the brain of the language user' (see also Jackendoff 2002). Note that theories of narrative text comprehension generally equate successful discourse comprehension with the construction of a coherent mental representation of the state of affairs described in the text at hand, that is, a situation model (e.g., Garnham 1981; Johnson-Laird 1983; Kintsch 1988; Zwaan and Radvansky 1998). 
The essential characteristic of a situation model is that it represents the people, objects, locations, events, and actions described in the text, not the words, phrases, clauses, sentences, and paragraphs that the text contains (e.g., Graesser et al. 1997; Zwaan and Radvansky 1998). Individual word meanings can convey a lot or only a little semantic content, and they do or do not pinpoint specific entities in the situation model. For example, both noun phrases and adjectives carry much semantic content, but only noun phrases pinpoint specific entities (adjectives can, however, aid in selecting an antecedent from multiple candidates). Not all noun phrases pinpoint a specific entity either. For example, although 'a doctor' in sentence (1a) and (1b) has the same general dictionary meaning (i.e., someone who completed medical school), 'a doctor' in (1a) sets up a new referent entity for some doctor who was being eaten, whereas it only provides information about Hannibal Lecter himself in (1b).

a. Hannibal Lecter is eating a doctor.

b. Hannibal Lecter is a doctor.

As many theorists have pointed out, some noun phrases (e.g., definite noun phrases like 'the doctor') are inherently referential, because they pick out an independent individual, while others are referential only by the virtue of their predicative role in the sentence (e.g., Donnellan 1966; Montague 1974; Partee 1987). Predicative noun phrases [as 'a doctor' in (1b)] do not pick out individuals, but behave like adjectives, contributing description but no new individual. Alternatively, some words do not really have a specific semantic meaning of their own and express meaning by being a referential device, for example, the pronoun 'it'. The pronoun 'it' refers to a 'CD' in both (2a) and (2b), but only in (2b) does it refer to the exact same copy of the new Coldplay CD John bought (see also Garnham 2001; Sanford and Garrod 1989).

(2) a. John bought the new Coldplay CD.

The next day Bill bought it too.

b. John bought the new Coldplay CD.

But the next day Bill stole it.

In short, words can carry referential claims insofar as they pinpoint specific discourse entities, either by forcing comprehenders to set up new referents or by referring to already known entities. Figuring out the referential relationships between words and entities in a story or conversation is a fundamental ingredient of discourse comprehension, because it allows comprehenders to keep track of who or what is being talked about.

\section{REFERENTIAL AMBIGUITY}

Although language users generally have little trouble establishing referential meaning in discourse, this is not always the case. In the current review, 
we will spotlight a specific problem with referential interpretation that arises whenever language users are unable to select a unique referent for an anaphor from multiple candidates, that is, referential ambiguity. For example, 'the nephew' is referentially ambiguous if two potential referents have been introduced in the story context (e.g., 'At the family get-together, Jim had been talking to one nephew who was very much into politics and another one who was really into history. But Jim himself was only interested in sports, cars, women etc. The nephew who was into politics.... Note that the referentially ambiguous expression 'nephew who was into' is disambiguated at 'politics').

Referential ambiguity appears to disrupt 'normal' language comprehension, yet this disruption is often only temporary (as in 'the nephew who was into politics'). Moreover, temporarily ambiguous situations are actually quite common in everyday language whenever a particular referent is singled out from several candidates (see also Auer 1984; Trueswell and Tanenhaus 2005; Brown-Schmidt and Tanenhaus forthcoming). Note that how language users refer to an entity depends on the saliency, specificity, and type of its perceptual features (e.g., Clark and Wilkes-Gibbs 1986; Brennan and Clark 1996; see also Sedivy 2002, 2003). For example, one could utter 'that blue t-shirt' among t-shirts with different colors, but one might say 'that t-shirt with the blue stripes' among t-shirts with different patterns, even though the latter expression is temporarily referentially ambiguous (the addressee will be unable to determine the antecedent at least during 'that t-shirt with the ...'). Importantly, referential ambiguity naturally emerges from how people use language in communication.

Referential ambiguity is also not uncommon in how people use pronouns. Because everyday language generally contains a multitude of discourse entities, pronouns are sometimes 'formally' ambiguous in the sense that the linguistic pronominal features (e.g., whether the pronoun is male/female, or singular/plural) do not logically warrant the retrieval of a unique antecedent. The shallow informational content that makes pronouns so easy to use for speakers is also what makes pronouns prone to ambiguity. In fact, pronouns can in some cases only be properly resolved 'downstream' (e.g., 'Al Gore kept reminding George Bush that, by popular vote, he had actually lost/won the presidential election'; see also Sanford and Garrod 1989). However, it should be noted that the interpretation of pronouns is often heavily determined by the preceding context (e.g., McKoon et al. 1993; Garnham 2001, for review), a phenomenon we will also explore in one of our experiments.

Theoretical accounts of anaphor resolution often assume that establishing anaphoric reference involves making an inference to maintain or restore referential coherence (Clark 1977; Garrod and Sanford 1977; McKoon and Ratcliff 1980; Greene et al. 1992; see Garnham 2001, for review). Although few accounts have explicitly addressed referential ambiguity, it stands to reason that resolving referential ambiguity also requires making 
an inference. Some accounts have addressed referential ambiguity while focusing on the role of linguistic and non-linguistic constraints on pronoun resolution. In general, an anaphoric inference is thought to be easier when one potential antecedent is especially prominent in the discourse (relative to competitor antecedents; for example, Grosz et al. 1995; Myers and O'Brien 1998). These inference processes have been formalized in some accounts (e.g., so-called 'construction rules' in Discourse Prominence Theory, Gordon and Hendrick 1998). In a recent computational model, Frank et al. (2007) simulated how the build-up of text coherence may lead to knowledge-based resolution of ambiguous pronouns (see also Hobbs 1979).

Note that some accounts of anaphor processing distinguish between the initial localization/identification of an antecedent, and the ultimate full commitment to one particular interpretation (so-called 'bonding' and 'resolution', respectively, see Garrod and Sanford 1999; Sanford and Garrod 1989; see also McKoon and Ratcliff 1980; Myers and O'Brien 1998, for related distinctions). In the prominent Bonding and Resolution framework (e.g., Sanford and Garrod 1989), however, it is unclear whether referential ambiguity should be thought of a problem primarily with bonding or with resolution. If a unique bond between anaphor and antecedent is required, referential ambiguity should be assumed to be a bonding problem. If simultaneous bonds are allowed, referential ambiguity should be thought of as a resolution problem instead. The latter idea is similar to an important assumption in memory-based processing models (e.g., Myers and O'Brien 1998; see also Kintsch 1988, 1998). In these models, anaphors automatically activate all antecedents that have features in common with the anaphor. When competing antecedents resonate in equal amounts, this referential ambiguity may trigger additional retrieval from episodic discourse memory, associated with a search for additional clues that might help to infer the most plausible referent.

\section{KEEPING TRACK OF REFERENTIAL AMBIGUITY}

Behavioral studies involving referential ambiguity are plentiful. Some studies have involved referential ambiguity to study antecedent accessibility using probe verification (e.g., Gernsbacher 1989; MacDonald and MacWhinney 1990). In probe verification, subjects read sentences containing pronouns (e.g., 'Jim predicted that Pam would lose the race but she came in first.'), and are asked to determine whether a probe word occurred in the sentence. When responses are compared for probe words presented before and after the pronouns, results show that pronouns facilitate recognition of antecedent probe words (e.g., 'Pam'), but inhibit recognition of non-antecedent probe words (e.g., 'Jim'). MacDonald and MacWhinney (1990) reported that these effects are substantially delayed for ambiguous pronouns, suggesting that it took subjects longer to find the correct antecedent. Although the probe verification task has been criticized for inducing task strategies that 
are not representative of how people normally process language (see Gordon et al. 2000; Guerry et al. 2006), these findings are generally consistent with people being slower in reading and comprehending sentences containing ambiguous pronouns (e.g., Rigalleau et al. 2004). In word-by-word selfpaced reading time studies, readers are known to specifically slow down at (i.e., have more trouble with the interpretation of) referentially ambiguous words (e.g., Myers and O’Brien 1998; Stewart et al. 2007).

A line of research that has been particularly productive is the visual world paradigm (e.g., Trueswell and Tanenhaus 2005, for review). In a typical visual world experiment, the subject is repeatedly instructed to select and move a specific object amid an array of objects, and his or her eye fixation behavior is recorded as the spoken instruction unfolds. The visual world paradigm was pioneered by Tanenhaus and colleagues (Tanenhaus et al. 1995; see also Cooper 1974), who showed that visual referential context has an immediate impact on syntactic parsing decisions (Tanenhaus et al. 1995; see also Altmann and Steedman 1988; Crain and Steedman 1985; Rayner et al. 1983; Spivey-Knowlton and Tanenhaus 1994, for discussion): when participants looked at a visual display that contained one apple on a towel and one empty towel, the syntactically ambiguous instruction 'Put the apple on the towel in the box' caused them to make incorrect eye-movements toward the empty towel (i.e., participants preferred the simpler 'destination' interpretation). However, when an apple on a napkin was added to the display, participants initially distributed their fixations across the two apples before settling on the apple on the towel, whereas they made almost no incorrect eye-movements toward the empty towel (i.e., participants preferred the 'location' interpretation). Later studies using this technique have consistently replicated that listeners who hear referentially ambiguous expressions evenly distribute their fixations across potential referents (e.g., Sedivy et al. 1999; Chambers et al. 2002; Spivey et al. 2002).

The study by Tanenhaus and colleagues (1995) subsequently sparked a very lively line of research wherein eye-movement responses are used to address the incremental and interactive nature of the human language processor (e.g., Sedivy 2003; Trueswell and Tanenhaus 2005, for reviews). One prominent topic is how rapid information that language users assume to share affects reference resolution ('common ground', for example, Clark 1996). When an addressee receives a - to him/her - referentially ambiguous instruction from a speaker who - according to the addressee - perceives no ambiguity (e.g., 'red triangle' when the addressee sees two red triangles but thinks that the speaker sees only one), an addressee immediately takes into account the speaker's perspective to establish reference (e.g., Hanna et al. 2003; see also Hanna and Tanenhaus 2004; Keysar et al. 2000; Nadig and Sedivy 2002). More recently, researchers have replicated these types of context effects in even more ecologically valid, unscripted conversational settings (Brown-Schmidt et al. 2008; Brown-Schmidt and Tanenhaus forthcoming). 
The abovementioned behavioral experiments clearly show that reading times and eye-movements reliably reflect some kind of processing difficulty when comprehenders encounter referentially ambiguous words. However, these measures do not provide qualitative information about underlying brain machinery. Note that qualitative information is important for understanding the exact reason why referentially ambiguous words are difficult to process. Without it, one could reasonably argue that readers slow down when reading 'the nephew' in a story with two nephews for other reasons than referential ambiguity. For example, readers may have expected the syntactically plural 'nephews', or perhaps they expected disambiguating information first (e.g., 'the older nephew'). Self-paced reading time data are unable to distinguish between these different accounts. With regard to eye-tracking methodology, the fact that people distribute eye-fixations across competing antecedents does suggest that they take into account multiple antecedents. However, fixation data do not shed any light on whether and to what extent referential ambiguity resolution involves the same neural processes as semantic and syntactic aspects of language comprehension.

In contrast to behavioral methods, neuroscience methods do offer the qualitative information needed to disentangle different aspects of language comprehension, and can allow inferences about the underlying neural mechanisms. In the experiments from our laboratory that will be reviewed here, we used ERPs and functional magnetic resonance imaging (FMRI) to study referential ambiguity. ERPs reflect the electrical activity directly generated by the brain (e.g., Rugg and Coles 1997), whereas FMRI reflects the magnetic signals that are dependent on blood oxygen levels that, in turn, are related to neural activity (e.g., Logothetis and Wandell 2004). We will briefly introduce FMRI methodology later in this review when we report our FMRI study on referential processing.

Event-related brain potentials are computed by averaging the brain's electrical voltage fluctuations (electro-encephalogram or EEG, as measured via electrodes at the scalp) that are time locked to certain events (e.g., words in an experimental condition). Reported ERP effects commonly pertain to the difference between the average amplitude of two experimental conditions within a time window of interest. ERPs provide quantitative and qualitative information about cognitive processes, because, in addition to the measurement of amplitude differences, their components can be classified according to polarity (negative/positive voltage), timing of the effect onset or maximum (onset or peak latency), morphology (slow rising or peaked), and distribution on the scalp surface (e.g., Rugg and Coles 1997). Another advantage of ERPs in psycholinguistic research (compared with traditional behavioral techniques like cross-modal priming and self-paced reading) is that they index language processing without the principled need for secondary tasks that may induce unnatural processing strategies. The most famous language-relevant ERP components are the 
N400 (Kutas and Hillyard 1980) and the P600 (Osterhout and Holcomb 1992), which have traditionally been associated with semantic and syntactic processing difficulty, respectively (e.g., Kutas and Van Petten 1994, for review). For a comprehensive review of the advantages (and disadvantages) of using ERPs to study discourse comprehension, see Van Berkum (2004).

Evidence that referential ambiguity has relatively unique processing consequences first came from an ERP study by Van Berkum et al. (1999). This ERP study addressed the immediacy with which referential context can impact syntactic ambiguity resolution, in a very similar way as some of the behavioral studies that we reviewed earlier (e.g., Tanenhaus et al. 1995). In this study, subjects read two types of stories (critical words are underlined for presentation purpose):

1-Referent context: Just as the elderly hippie had lit up a joint, he got a visit from a friend and a nephew. Even though his friend had had quite a few drinks already, and the nephew had just smoked quite a lot of pot already, they insisted on smoking along. The hippie warned the friend that there would be some problems soon.

2-Referent context: Just as the elderly hippie had lit up a joint, he got a visit from two friends. Even though one of his friends had had quite a few drinks already, and the other one had just smoked quite a lot of pot already, they insisted on smoking along. The hippie warned the friend that there would be some problems soon.

Note that both stories are completely syntactically correct even though 'The hippie warned the friend that' is temporarily ambiguous as to whether it is followed by a complement clause that will specify the warning (as in the 1-referent context), or by a relative clause providing additional information about the friend. In a 1-referent context, people prefer the simpler complement clause interpretation (e.g., Ferreira and Clifton 1986; Brysbaert and Mitchell 1996). However, people prefer the relative clause interpretation in a 2-referent context, because 'friend' is then referentially ambiguous and additional information is expected (e.g., Crain and Steedman 1985; Spivey-Knowlton and Tanenhaus 1994). Note that in the 2-referent context, a complement clause like 'the friend that there...' does not resolve the referential ambiguity, and constitutes a syntactic garden path at the word 'there'. In the Van Berkum et al. study (1999), referentially ambiguous words (e.g., 'friend' in the 2-referent context) elicited a sustained, negative ERP effect with a strongly frontal distribution (maximal effect near the forehead). This sustained negative effect was already visible in the ERP waveforms within $280 \mathrm{~ms}$ after the referentially ambiguous word. The subsequent word 'there' in the 2-referent context (compared to 'there' in the 1-referent context) elicited a P600 effect, which is consistent with a syntactic garden path effect (see also Osterhout et al. 1994). The observation of a sustained negative effect following 
referential ambiguity was subsequently replicated with spoken nouns (see Van Berkum et al. 2003). For present purposes, the Van Berkum et al. (1999, 2003) results harbor two critical findings. First, readers and listeners very rapidly determine whether an anaphor has a single unique referent in the discourse or not, and second, referential ambiguity entails processing costs that are qualitatively distinct from those imposed by semantically or syntactically problematic words (that elicit N400 and P600 effects, respectively).

ERP REFLECTIONS OF REFERENTIAL AMBIGUITY AT THE LEVEL OF THE DISCOURSE MODEL

The discovery of a relatively unique ERP signature of referential ambiguity could open up new ways of studying referential processing in language comprehension. However, the usefulness of this ERP effect (from hereon the 'Nref' effect) as a tool to track referential processing hinges on the level of ambiguity it reflects. The Nref effect may reflect 'deep' ambiguity from having two equally plausible referential candidates for a single anaphor in the situation model of the discourse (e.g., Zwaan and Radvansky 1998). In this case, the Nref effect could actually inform psycholinguists about the discourse-level changes in referential accessibility of story characters. However, it may also reflect a more 'superficial' ambiguity at the level of memory for text ('textbase'; for example, Kintsch 1998; Myers and O'Brien 1998) that arises, because a single lexical concept ('the nephew') is associated with two entities in episodic discourse memory. In this alternative scenario, the Nref effect would not be sensitive to whether both discourse entities are equally plausible referents.

We resolved this issue in an ERP study that followed up on the Van Berkum et al. (1999) results (Nieuwland et al. 2007a). Subjects listened to short stories describing a protagonist and two secondary characters engaged in conversation. Three story types were created by manipulating the denotation of the secondary characters (identical or non-identical nouns) and/or the story content (one secondary character did or did not leave the current situation; see Table 1). Every story contained two noun phrases that referred to one of the secondary characters at different story positions. The noun phrases at the two story positions had only one possible referent in the 1-1 referent condition (both non-ambiguous), but two possible referents in the 2-2 referent condition (both ambiguous). In the 2-1 referent condition, the first noun phrase was ambiguous, while the second noun phrase was non-ambiguous (given that readers routinely represent the location of a foregrounded story protagonist; for example, Zwaan and Radvansky 1998). Thus, we hypothesized that if the Nref effect reflects genuine discourse-level referential ambiguity, it should re-appear at the second story position in the 2-2 referent condition but not in the 2-1 referent condition. 
Table 1. Example story (adapted from Nieuwland et al. 2007a). Critical anaphors at story positions 1 and 2 are underlined. Non-ambiguous anaphors are printed in italics, temporarily referentially ambiguous anaphors are printed in boldface.

1-1 Referent condition: non-ambiguous at both story positions

At the family get-together, Jim had been talking to his nephew who was very much into politics and his uncle who was really into history. But Jim himself was only interested in sports, cars, women etc. The uncle who was into history left early, but the nephew who was into politics kept rambling on. Jim didn't understand one bit and got rather bored. He told the nephew who was into politics that politicians should not systematically neglect delightful and important subjects like sports and women.
2-2 Referent condition: ambiguous at both story positions

At the family get-together, Jim had been talking to one nephew who was very much into politics and another one who was really into history. But Jim himself was only interested in sports, cars, women etc. The nephew who was into history kept telling boring stories, and the other one also kept rambling on. Jim did not understand one bit and got rather bored. He told the nephew who was into politics that politicians should not systematically neglect delightful and important subjects like sports and women.
2-1 Referent condition: Ambiguous at position 1, non-ambiguous at position 2 At the family get-together, Jim had been talking to one nephew who was very much into politics and another one who was really into history. But Jim himself was only interested in sports, cars, women etc. The nephew who was into history left early, but the nephew who was into politics kept rambling on. Jim did not understand one bit and got rather bored. He told the nephew who was into politics that politicians should not systematically neglect delightful and important subjects like sports and women. 

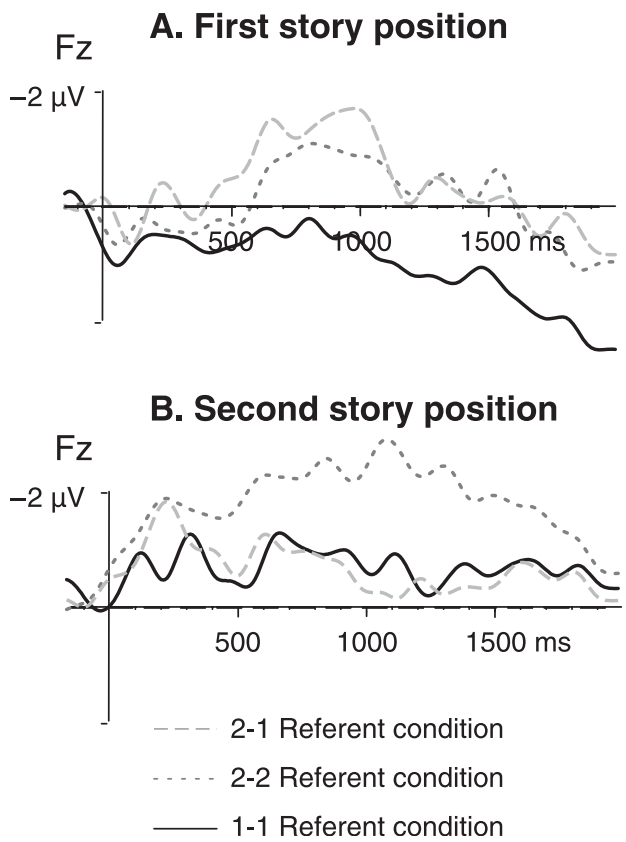

Fig. 1. (A) ERPs at frontal electrode Fz for the three conditions at story position 1, (B) and at story position 2. Figure $1 A-B$ has been adapted from Nieuwland et al. (2007a). In this and all following figures, negativity is plotted upward, waveforms are filtered ( $5 \mathrm{~Hz}$ high cut-off, 48 $\mathrm{dB} / \mathrm{oct}$ ) for presentation purpose only.

Figure 1 shows the ERPs for the different conditions at both story positions. At the first story position (Figure 1A), ambiguous words (noun phrases in the 2-1 and 2-2 referent condition, compared with noun phrases in the 1-1 referent condition) elicited the same Nref effect as reported by Van Berkum et al. $(1999,2003)$. At the crucial second story position (Figure 1B), however, critical noun phrases in the 2-2 referent condition still elicited the Nref effect, but critical noun phrases in the 2-1 referent condition did not. These results show that referential processing can be tracked at the level most relevant for discourse comprehension, the situation model.

Note, however, that one piece of the puzzle remains to be addressed, namely, whether ERPs reflect how comprehenders ultimately establish reference. In the Nieuwland et al. (2007a) study, the Nref effect outlasted the temporary ambiguity itself. Taking into account that the mean distance between critical nouns and the disambiguating words was 1,083 $\mathrm{ms}(\min =673 \mathrm{~ms}, \max =1,139 \mathrm{~ms})$, the effects of ambiguity as shown in Figure 1 clearly persist well beyond that point. In addition, the ERPs that were time-locked to the disambiguating words (e.g., 'politics') did not show any immediate effect of ambiguity resolution. One could argue that these results show that listeners maybe did not resolve ambiguity where 
one would expect them to. However, this is unlikely in view of what is known about the incremental nature of anaphor resolution (e.g., Tanenhaus et al. 1995; Altmann and Kamide 1999). Instead, our seemingly paradoxical results suggest that the increased processing load due to referential ambiguity has relatively long-lasting effects on language processing (see also Kutas 1997). Thus, while making a demand on processing capacity has an immediate effect, this demand seems to disappear more gradually.

\section{CONTEXTUAL BIAS AND INDIVIDUAL DIFFERENCES IN REFERENTIAL PROCESSING}

Having established what level of ambiguity the Nref effect reflects, we employed it to examine effects of sentence context and individual differences in pronoun processing. Pronouns are often regarded as the textbook example of referential processing, and are known to provide language users with a fast and easy way to refer to entities that are important in a conversation or story. In fact, comprehending pronouns is such common practice, readers and listeners usually feel as if they understand their antecedents immediately (e.g., Clark and Sengul 1979). Interestingly, language comprehenders generally do not even notice that the co-reference relations between pronouns and their antecedents in everyday language are often 'formally' ambiguous. For example, most people will immediately take 'he' in 'Al Pacino hated Bruce Willis because he ...' to refer to 'Bruce Willis' (as they expect information about why Bruce Willis was hated), whereas 'he' could logically refer to either actor. Generally, the discourse context allows comprehenders to immediately determine the antecedent, and these contextual effects can be observed even in simple sentences:

(4) a. Al Pacino hated Bruce Willis because he...

b. Al Pacino secretively whispered to Bruce Willis because he ...

c. Al Pacino told Bruce Willis that he...

When asked to complete these sentence fragments, people will, on average, complete (4a) so that 'he' refers to 'Bruce Willis', complete (4b) so that 'he' refers to 'Al Pacino', and complete (4c) so that 'he' refers equally often to the two actors. This means that the sentence context can bias readers toward a particular referential interpretation, a phenomenon we call contextual bias $[(4 a-b)$ have a strong contextual bias, whereas $(4 c)$ has a weak contextual bias]. Contextual bias reflects the syntactic and semantic/pragmatic constraints from the preceding context that bring one antecedent into discourse focus, at the expense of the other (see Garnham 2001; Koornneef and Van Berkum 2006, for discussion).

As reported by Van Berkum et al. (2004), ambiguous pronouns elicit the same Nref effect as ambiguous noun phrase anaphors. In a follow-up ERP study, we examined whether a strong contextual bias would affect the likelihood that readers take into account both referential interpretations of 
an ambiguous pronoun (Nieuwland and Van Berkum 2006). Subjects read sentences containing referentially unique or ambiguous pronouns, and the sentences had either a weak or strong contextual bias. This bias had been assessed in an independent pre-test wherein subjects completed sentence fragments ending with ambiguous pronouns [see $(4 a-c)]$ and indicated whether they had the first- or second-mentioned character in mind during completion. Sentences that many subjects completed with the same character in mind had a strong contextual bias, whereas sentences where subjects had no overall preference had a weak contextual bias.

For the ERP experiment, we predicted that the amplitude of the Nref effect would show a negative correlation with contextual bias, because the chance that a subject will take into consideration two competing antecedents diminishes when one antecedent is in greater focus than the other (e.g., Garnham 2001). In addition to these context effects, we examined whether taking into account both referential interpretations depended on languageprocessing skills, as good readers are generally more sensitive to subtle linguistic phenomena than poor readers (e.g., MacDonald and Christiansen 2002). We assessed language processing skills with the reading span test, which is known to strongly correlate with on-line and off-line of measures of reading comprehension skills ${ }^{1}$ (e.g., Daneman and Carpenter 1980; Just and Carpenter 1992; MacDonald and Christiansen 2002). In terms of ERPs, if high-span readers take into account multiple referential interpretations more often than low-span readers, a larger Nref effect should be observed for high-span vs. low-span readers.

The ERP results supported both of our predictions (see Figure 2). Ambiguous pronouns elicited a larger Nref effect in sentences with a weak contextual bias vs. a strong contextual bias (Figure 2A), and also in highspan readers vs. low-span readers (Figure 2B; there was no interaction between contextual bias and span group). Moreover, the size of the Nref effect was negatively correlated with contextual bias, and positively correlated with reading span score. Thus, our results suggest that whether a reader actually takes into account both interpretations of a formally ambiguous pronoun is subtly determined by both individual language-processing skills and contextual bias.

THE INTERACTION OF SEMANTIC AND REFERENTIAL ASPECTS OF ANAPHORIC NOUN PHRASE RESOLUTION

The aforementioned ERP results show that sentence- and discourse-level semantic manipulations can preclude readers from taking into account multiple referential interpretations for a given anaphor. Clearly, reference resolution is also strongly driven by the semantic properties of the anaphor itself. It has long been recognized that semantic and referential analysis co-determine the interpretation of anaphoric noun phrases (e.g., Garrod and Sanford 1994; Garnham 2001), and, more generally, that semantic and 


\section{A. Effects of contextual bias}
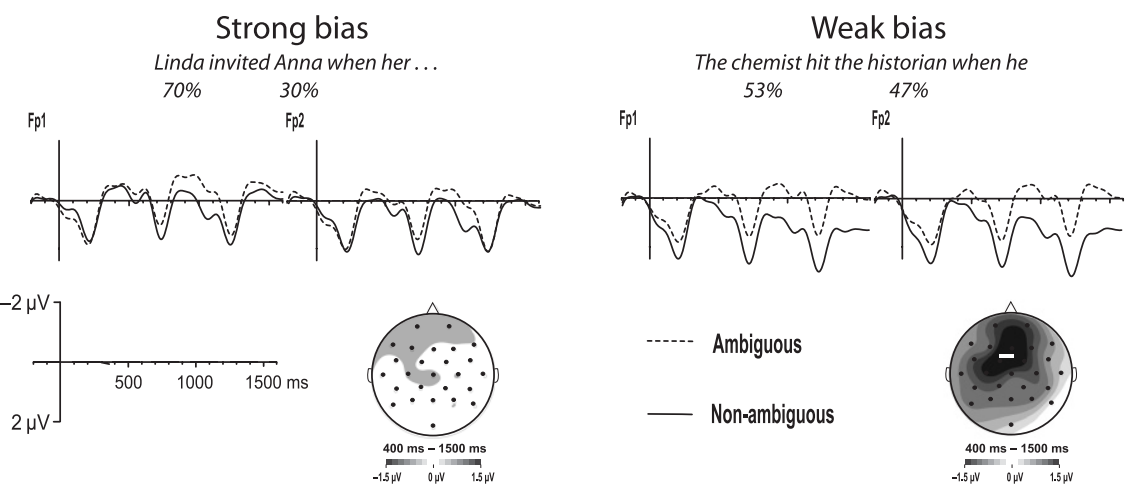

B. Effects of reading span

Low reading span
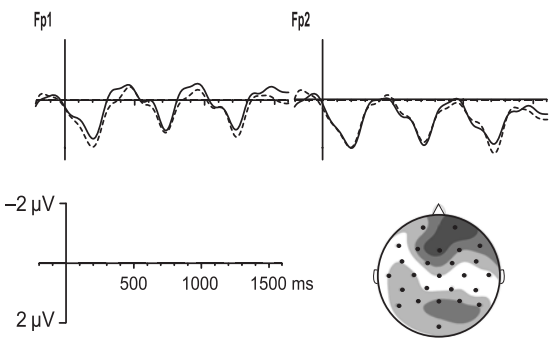

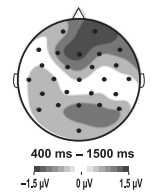

High reading span
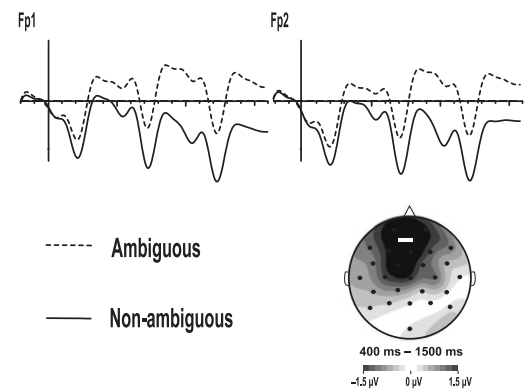

Fig. 2. (A) ERPs for the ambiguous and non-ambiguous pronouns in sentences with a strong or weak contextual bias. Numbers below the sentence entities indicate contextual bias: the pre-test results showed that $70 \%$ of the subjects completed the left-hand sentence with 'Linda' in mind and 30\% with 'Anna' in mind. An approximately equal percentage of subject completed the right-hand sentence with 'the chemist' or 'the historian' in mind. Scalp distributions of both effects are given below. (B) ERPs for the ambiguous and non-ambiguous pronouns in the low and high reading span group. Scalp distributions of the effects in both groups are given below. Figure 2A-B has been adapted from Nieuwland and Van Berkum (2006).

referential aspects of language comprehension are intricately interwoven at the functional level (e.g., Jackendoff 2002). To further investigate the interplay and mutual dependence of semantic and referential analysis in a direct way, we conducted an ERP study that orthogonally manipulated the semantic and referential status of anaphors (Nieuwland and Van Berkum forthcoming). Subjects listened to a story introduction that contained two similar or dissimilar entities, and subsequently read a final sentence containing a semantically coherent or incoherent anaphoric noun phrase. As shown in Table 2, these anaphors were thus either only referentially ambiguous, only semantically incoherent, both ambiguous and incoherent, or both unambiguous and coherent. 


\section{Table 2. Example item (adapted from Nieuwland and Van Berkum forthcoming). Critical noun phrase anaphors are underlined for expository purpose.}

\author{
1-Referent introduction, dissimilar discourse \\ entities: \\ Britney Spears had several pieces of jewelry, \\ including a golden necklace and a silver \\ bracelet. One day she was about to leave \\ for a gala.
}

\author{
2-Referent introduction, similar discourse \\ entities: \\ Britney Spears had several pieces of \\ jewelry, including a golden necklace and \\ a silver one. One day she was about to \\ leave for a gala.
}

Semantically incoherent anaphor:

She stepped into the necklace when suddenly her date called to cancel.

Semantically coherent anaphor:

She was admiring the necklace when suddenly her date called to cancel.

We predicted to see an Nref effect for referential ambiguity, and an N400 effect for semantic incoherence (each compared to the fully coherent control condition). For the combination of referential ambiguity and semantic incoherence, we distinguished a number of possibilities. First, a problem with semantic analysis might preclude readers from making anaphoric inferences associated with referential ambiguity, as readers might devote all of their attentional resources to re-establishing semantic coherence. If readers indeed fail to resolve the 'full' referential implications of an ambiguous anaphor (e.g., Levine et al. 2000; Klin et al. 2004), the simultaneously ambiguous and incoherent anaphors would elicit an N400 effect but no Nref effect. Alternatively, the combined presence of ambiguity and incoherence might 'boost' the impact of either ambiguity or incoherence. One could argue that the combination of ambiguity and incoherence makes those anaphors even less expected than separately incoherent anaphors, in which case one would predict a boosted N400 effect (see also Hagoort 2003, for a 'syntactic boost' effect of syntactic anomalies on the N400 effect elicited by semantic anomalies). Resolving ambiguity may also be more difficult when both referential candidates are implausible (as there are even fewer proper cues to which antecedent fits the antecedent best), in which case one would predict a larger Nref effect for the combined condition than for ambiguity alone. ${ }^{2}$ Finally, it might be the case that referential ambiguity resolution is relatively independent of semantic analysis so long as the latter process does not readily provide clues to resolve the ambiguity. In this case, referential ambiguity resolution proceeds undisturbed in the face of semantic violations, causing the combined violations to elicit both an Nref effect and an N400 effect.

As shown in Figure 3, our predictions for referential ambiguity and semantic incoherence separately were confirmed by our results (an Nref effect for referential ambiguity, an N400 effect for semantic incoherence). The 


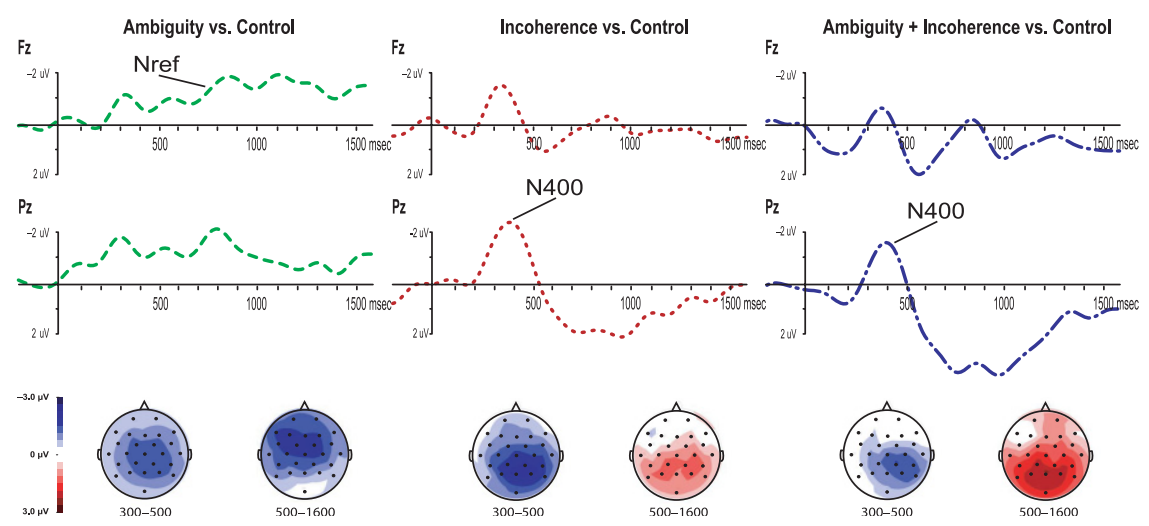

Fig. 3. Difference waves of ambiguity, incoherence, and ambiguity/incoherence (compared with the control condition) at $\mathrm{Fz}$ and $\mathrm{Pz}$, the corresponding scalp distributions in the 300-500 ms and 500-1600 ms time windows, and relevant ERP effect labels. Figure 3 has been adapted from Nieuwland and Van Berkum (forthcoming) and displays the ERP results only for the group of participants that did not show an unexpected late positive ERP effect to referential ambiguity.

critical comparison involving the simultaneously ambiguous and incoherent anaphors, however, yielded an N400 effect but no Nref effect. ${ }^{3}$

Our ERP studies thus show that referential ambiguity is precluded when one referential candidate is strongly preferred over the other, but also when they are equally unlikely (i.e., incoherent). The latter finding suggests that readers set out to work on the most salient and important coherence break, as semantically incoherent anaphors impose powerful disruptions of comprehension, whereas ambiguous anaphors are merely incomplete (see also Nieuwland and Van Berkum 2006). Perhaps due to the limited capacity of the language processor, re-establishing semantic coherence led subjects to disregard the 'smaller concern' imposed by referential ambiguity.

Our results thus provide evidence that taking into account multiple referential candidates (as reflected by the referentially induced ERP effect) involves making an anaphoric inference (Nieuwland and Van Berkum 2006; see also Greene et al. 1992). More importantly, our results clearly indicate that one aspect of conceptual interpretation, semantic analysis, can proceed when another aspect of conceptual processing, referential analysis, cannot deliver a unique referent over which semantic analysis is ultimately defined.

THE FUNCTIONAL NEUROANATOMY OF DEALING WITH REFERENTIAL AMBIGUITY

ERPs clearly distinguish between the processing consequences of referentially ambiguous words and syntactically or semantically problematic words. However, because the brain's electrophysiological signals are 'smeared' by 
its tissue and summate at the scalp surface, ERPs are not very informative to which cortical networks are involved in establishing reference, or what their relationship is to the networks known to process semantic meaning. To answer these types of questions, researchers have started using FMRI techniques (e.g., Huettel et al. 2004). FMRI involves the non-invasive registration of blood oxygenation level-dependent signal changes. Neuronal activity increases lead to an increased demand for oxygen (which is delivered by hemoglobin in capillary red blood cells), and the local response is an increase in blood flow to regions of increased neural activity (the hemodynamic reponse). Hemoglobin's magnetic properties depend on the oxygen it contains, and as blood oxygen levels vary according to the levels of neural activity, the resulting difference in magnetic properties can be used to detect activity changes in the brain. As with ERPs, the general approach in FMRI is to compare signal changes between two or more conditions. Due to the slow nature of the hemodynamic response, however, the temporal resolution of FMRI is relatively poor (in the order of seconds) compared to the millisecond resolution of EEG/ERP. But in contrast to ERPs, FMRI can provide maps of where in the brain relative activation increases and decreases occur, with a spatial resolution of only a few millimetres.

In an FMRI study (Nieuwland et al. 2007b), we examined the brain regions that would become more active following referentially ambiguous pronouns compared to referentially coherent pronouns [e.g., 'he' in (5a) vs. (5b)].

(5) a. Ronald told Frank that he had a positive attitude towards life.

b. Ronald told Emily that he had a positive attitude towards life.

This study of functional neuroanatomy allowed us to contrast two notions of what it means to deal with referential ambiguity. One could argue that referential ambiguity requires readers to retain competing interpretations in working memory until decisive information follows. In this case one would particularly predict more activation in the left inferior frontal gyrus (LIFG), an area that has been implicated in working memory processes (e.g., Fletcher and Henson 2001) and also in the detection and resolution of incompatible stimulus representations (Novick et al. 2005). Alternatively, if people evaluate the two referential interpretations in order to restore coherence (e.g., Hobbs 1979; Greene et al. 1992; Frank et al. 2007), one would predict activation in brain regions associated with evaluation and inference procedures (medial prefrontal and parietal activations; for example, Zysset et al. 2003; Ferstl 2007). As shown in Figure 4A, our FMRI results are most consistent with the second account: referential ambiguity did not elicit additional activations in the LIFG but in medial prefrontal and parietal regions. These results suggest that subjects made an anaphoric inference in order to re-establish referential coherence (Greene et al. 1992). 
(A)

Referential ambiguity $>$ Referential coherence
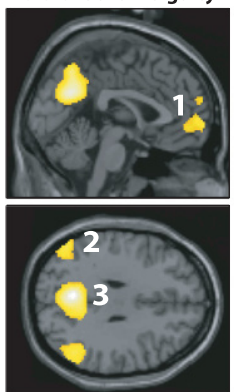

[0 26 30]
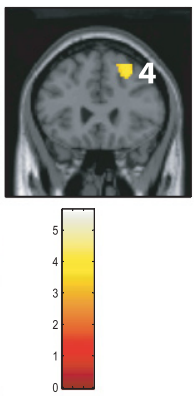

1. Anterior medial prefrontal (BA 10)

2. Bilateral parietal (BA 39)

3. Medial parietal (BA 7/31)

4. Right dorsolateral (BA 8/9)

(C)

Semantic anomaly $>$ Semantic coherence
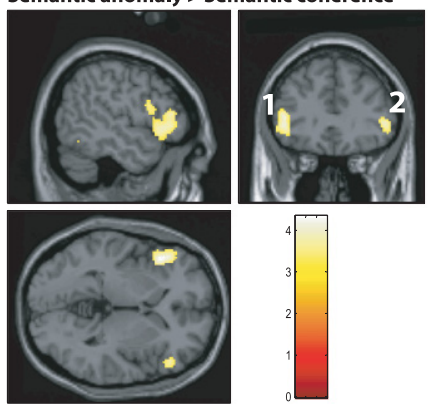

$[-50,32,0]$

1. Left inferior prefrontal (BA 44/45/47)

2. Right inferior prefrontal(BA 45)

(E)

Referential failure $>$ Referential coherence
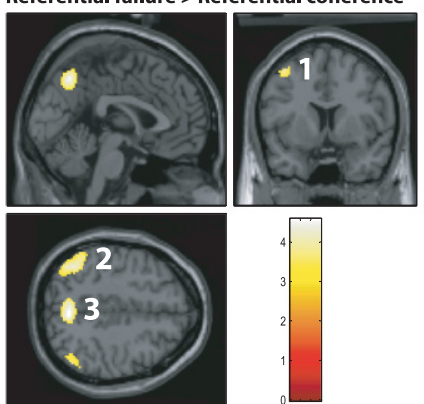

[0 8 46]

1. Left middle frontal (BA 6/8)

2. Bilateral parietal (BA 39)

3. Medial parietal (BA 7/31)
(B)

Referential ambiguity $<$ Referential coherence
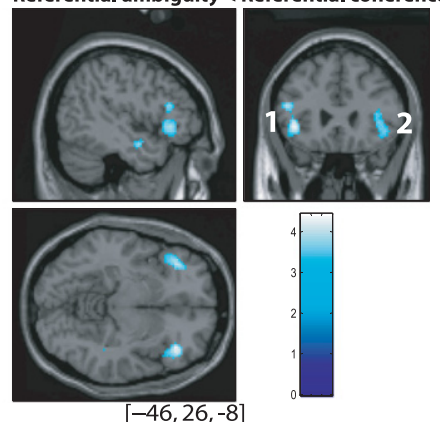

1. Left inferior prefrontal (BA 45/47)

2. Right inferior prefrontal(BA 45/47)

(D)

Semantic anomaly $<$ Semantic coherence
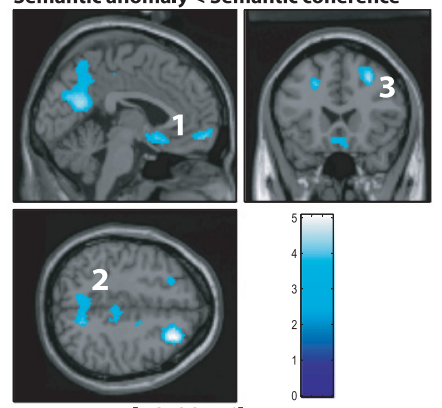

$[-2,22,46]$

1. Anterior medial prefrontal (BA 10/11/25)

2. Medial parietal (BA 7/30/31)

3. Right dorsolateral (BA 8/9)

(F)

Third-person interpretation
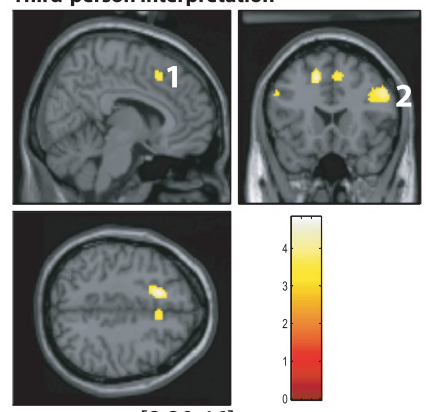

[8 20 46]

1. Medial superior frontal (BA 8)

2. Right middle frontal (BA 9/46)

Fig. 4. (A-E) Pair-wise comparisons across all subjects. (F) Brain regions that are more active when subjects adhere a third-person interpretation for referentially failing pronouns, computed as a double subtraction: Group 1 [Failure-Coherence] - Group 2 [Failure-Coherence]. Figure 4A-F has been adapted from Nieuwland et al. (2007b). 
In addition, they suggest that the processing consequences of referential ambiguity are qualitatively different from those imposed by verbal working memory manipulations (e.g., Fletcher and Henson 2001) or conflicting semantic representations (e.g., Novick et al. 2005).

With regard to semantic processing, we made another interesting observation. Not only did the networks activated by referential ambiguity not overlap with the network activated by a standard semantic anomaly (e.g., Ronald told Emily that he had a positive potato towards life.), we actually observed a double dissociation. That is, the systems that showed relative activation increases to semantic anomaly (left and right inferior frontal gyrus) showed relative activation decreases to referential ambiguity, and vice versa (see Figure 4A-D). This inverse coupling pattern warrants further investigation (e.g., using functional connectivity analysis), but may reflect the relative contributions of semantic and episodic processing (e.g., Bookheimer 2002; Wagner et al. 2005) to re-establish semantic and referential coherence, respectively.

BUT WHAT IF THERE ARE TOO FEW SUITABLE REFERENTS?

Our ERP and AMRI results have yielded novel insights into how the human brain deals with referential ambiguity in language comprehension. However, the present focus on referential ambiguity clearly does not do justice to the complex functional and neural implementation of referential processing as a whole. There are many aspects to referential processing that may rely on different linguistic and non-linguistic processing streams to different degrees (e.g., Gernsbacher 1989; Ariel 1990; Almor 1999; Jarvikivi et al. 2005). For example, over-specific repeated-name anaphors (e.g., John went to the store after John ...) generally evoke N400 effects, reflecting the conflict between general memory mechanisms and the role of discourse prominence in anaphor resolution (Swaab et al. 2004). Another example is when the co-reference binding between pronoun and antecedent is problematic not because there are too many suitable referential candidates but because there are too few (i.e., referential failure).

Referential failure may occur when a pronoun does not match the gender of its antecedent. For example, 'himself' in 'The woman asked himself' elicits a P600 effect, signaling that people ascribe the referential failure to the morpho-syntactic gender of the pronoun (e.g., Osterhout 1997; Harris et al. 2000). Interestingly, pronouns that do not formally require an antecedent within the same sentence (i.e., 'unbound' pronouns) also elicit a P600 effect when their gender mismatches that of the directly available antecedents (e.g., 'he' in 'The woman said that he' or in 'Mary told Lisa that he'; Osterhout and Mobley 1995; Van Berkum et al. 2004; Nieuwland and Van Berkum 2006). This suggests that readers try to find an appropriate antecedent within the given set of discourse entities (e.g., Garnham 2001) and therefore initially ascribe the referential failure to a 
problem with the syntactic gender of the pronoun. These results are consistent with the notion that the P600 ERP is sensitive not just to syntactic rule violations but syntactic preference violations too (e.g., Osterhout et al. 1994).

An interesting extension of these results is that semantic verb information can lead to temporary referential failure even in the presence of a clear-cut antecedent (Van Berkum et al. 2007). Some verbs supply implicit, but potent information about whose behavior or state is the likely cause of the described event (i.e., implicit causality; Garvey and Caramazza 1974). For example, 'inspire' in the segment fragment 'David inspired Lisa because ...' makes readers focus on 'David' as he is the most obvious cause of Lisa's inspiration (see Koornneef and Van Berkum 2006 for evidence from eye-tracking), even though the rest of the sentence may very well be about 'Lisa' (e.g., 'because she also wanted to be an architect'). Interestingly, pronouns that do not correspond to these shifts in focus (e.g., Lisa inspired David because he ...) elicit a P600 effect compared to pronouns that do correspond to these shifts (e.g., 'David inspired Lisa because he ...'; Van Berkum et al. 2007). These results underscore the notion that referential resolution runs smoothly only when a pronominal anaphor uniquely maps onto an antecedent that is in the current focus of the discourse.

The notion that the brain initially treats referentially failing pronouns as morpho-syntactic violations received additional support from our FMRI data (Nieuwland et al. 2007b). Failing pronouns specifically led to relative activation increases in brain regions sensitive to morpho-syntactic violations (see Figure 4E; see also Ni et al. 2000; Kuperberg et al. 2003). In addition to this specific modulation, referential failure led to relative activation increases in medial and bilateral parietal brain regions that also were activated by referential ambiguity. Consistent with the presumed role of these regions in episodic memory processing (e.g., Wagner et al. 2005), these overlapping activations could reflect that readers rely on episodic discourse memory to resolve a referentially problematic situation (e.g., Myers and O’Brien 1998).

Interestingly, whereas subjects were not specifically instructed about how to deal with failing pronouns, our post-experiment debriefing suggested that some subjects resolved the failure by 'blaming' the syntactic gender of the pronoun, whereas others had consistently invoked a third, unmentioned person (e.g., 'he' could be taken to refer to Rose's new boyfriend). As shown in Figure 4F, these third-person anaphoric inferences were associated with additional activations in brain regions that are also associated with causal inferences (e.g., Kuperberg et al. 2006), and may signal the extent to which readers generate information themselves to 'fill in the blanks' during discourse comprehension.

Note that our functional neuroimaging results on referential failure and ambiguity show that referential analysis during sentence comprehension draws upon brain regions beyond the 'traditional' temporal-frontal language 
network (see also Mason and Just 2006; Ferstl and Siebörger 2007; Ferstl et al. 2008). Current neurocognitive models of syntactic (e.g., Friederici 2002) or semantic processing (e.g., Jung-Beeman 2005) are not yet equipped to deal with referential processing. A complete neurocognitive account of language comprehension will have to address not just how language comprehenders parse a sentence and combine the meaning of the individual words, but also how they determine who is who and what is what during language comprehension.

\section{Conclusions}

We reviewed a series of neurocognitive experiments from our laboratory that focused on referential ambiguity in sentence and discourse comprehension. Referential ambiguity arises whenever language comprehenders are unable to select a unique referent for a linguistic expression from multiple candidates. Temporary referential ambiguity is not uncommon in the everyday use of noun phrases and pronouns, and naturally emerges from how people use language for communication. It poses a unique challenge to the human language processor that goes beyond syntactic and semantic processing, and has a relatively distinctive impact on neural processing, as reflected in the frontally distributed, sustained Nref ERP effect. In our studies, we have shown that the Nref effect reflects genuine ambiguity at the level that is most relevant to discourse comprehension, the situation model. This means that ERPs can be used to selectively track when readers and listeners actually take into account multiple antecedents for a single referential expression.

Note that problems with semantic and referential analysis both involve interpretive aspects of communication. Some accounts of comprehension have assumed that listeners recover the speaker's meaning in similar ways regardless of whether an utterance is underspecific, overspecific, or plainly incoherent (i.e., through implicatures that derive what a speaker intended to communicate; for example, Grice 1975). Clearly, the results from some of the studies that we reviewed here show a more complex picture. By using neurocognitive methods that probe qualitative aspects of information processing in the brain, we have been able to show that the brain somehow honors what it is that makes an utterance hard to understand.

Employing the Nref effect, we showed that the likelihood that readers take into account multiple referential interpretations for pronouns increases with language processing skills, but subtly decreases with contextual bias toward one particular referential interpretation. In addition, we used this effect to show that, under certain circumstances, semantic analysis can proceed without regard for the unique outcome of referential analysis. There are also caveats to the usability of the Nref effect, however, as the impact of referential ambiguity on the ERP is relatively weak (especially compared to those of semantic or syntactic violations), and the Nref effect 
appears limited to tracking the onset but perhaps not the ultimate resolution of referential ambiguity.

Our functional neuroanatomical examination of referential processing revealed that dealing with referential ambiguity leads to relative activation increases in brain regions associated with making discourse-level inferences. These results are consistent with the notion that readers engage in problem solving to select a unique referent for an ambiguous expression. Furthermore, the neural systems that deal with referential ambiguity partially overlap with those that deal with referential failure, possibly reflecting common underlying episodic memory processes. In contrast, the networks showing activation increases to referential ambiguity show relative decreases to semantic anomaly and vice versa, which may reflect the relative contributions of semantic and episodic processing to re-establish semantic and referential coherence, respectively.

We have also briefly addressed the situation that there are too few instead of too many suitable candidates. The results from our neurocognitive studies suggest that readers and listeners can ascribe the failure to find any suitable antecedent for a pronoun to its morpho-syntactic gender. At least initially, that is, as some people generated new story information to resolve referential failure instead of simply 'blaming-the-syntax'. Intriguingly, when pronoun refers to antecedents that are out of discourse focus, temporary referential failure may occur even in the presence of a clear-cut antecedent.

At a more general level, our results show that cognitive neuroscience can extend the scientific understanding of referential processing beyond what is known from behavioral psycholinguistic research. However, observing what referential processing does to our brain, eye-movements or to button-press behavior can only take psycholinguists so far. It is becoming increasingly clear that, to account for the available data and make critical progress, there is a need for finer-grained models of anaphoric processing. For referential ambiguity in particular, the inference processes that are assumed to underlie referential ambiguity resolution remain as yet underspecified in most psycholinguistic accounts of anaphoric processing (e.g., Gordon and Hendrick 1998; Myers and O’Brien 1998; Almor 1999; Garrod and Sanford 1999; see also Garnham 2001). Some progress has been made with explicit computational models of ambiguity resolution (Frank et al. 2007), although these models do not yet incorporate realistic amounts of the knowledge that people bring to bear during real-time comprehension. On the 'brain side' of things, researchers are only just starting to grasp the complex implementation of discourse-level processing in the brain (e.g., Mason and Just 2006; Ferstl et al. 2008). An important task that lies ahead is bridging theoretical, computational and neuroscience approaches (e.g., O'Doherty et al. 2007; Reichle and Mason 2007). Such an integrative approach will be important for researchers to address the dynamic interplay of language, memory, and reasoning processes that support referential processing. 


\section{Acknowledgements}

The research by Mante S. Nieuwland and Jos J. A. Van Berkum as reviewed in this article was conducted at the University of Amsterdam Psychology Department, and supported by an NWO Innovation Impulse VIDI grant to Jos J. A. Van Berkum. Mante S. Nieuwland is currently funded by a Rubicon grant from the Netherlands Organization for Scientific Research (NWO).

\section{Short Biography}

Mante Nieuwland is a post-doctoral researcher at Tufts University (Medford, MA, USA) and the Athinoula A. Martinos Center for Biomedical Imaging (Charlestown, MA, USA). His experimental work on referential ambiguity as reviewed here was part of his $\mathrm{PhD}$ thesis, and was done under the supervision of Jos Van Berkum. His current research focuses on the interplay of pragmatic constraints and real-world knowledge during language comprehension.

Jos Van Berkum is senior researcher at the Max Planck Institute for Psycholinguistics, and Research Fellow at the FC Donders Centre for Cognitive Neuroimaging, both in Nijmegen, the Netherlands. His current research focuses on the neurocognition of language interpretation in context.

\section{Notes}

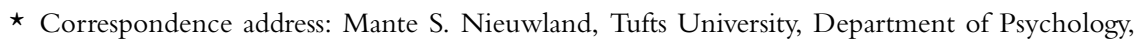
490 Boston Avenue, Medford, MA 02155, USA. E-mail: mante@nmr.mgh.harvard.edu.

${ }^{1}$ Although the reading span test has traditionally been used to assess working memory performance (e.g., Daneman and Carpenter 1980), the concept and measurement of working memory capacity remains a topic of debate (e.g., Caplan and Waters 1999; Engle 2002; MacDonald and Christiansen 2002). Here, we follow a 'processing skill' account of individual differences in language comprehension (e.g., MacDonald and Christiansen 2002).

${ }^{2}$ One could also argue for a combination of the two last possibilities wherein both the N400 effect and the Nref are 'boosted'.

${ }^{3}$ This conclusion holds for those subjects that show regular ERP responses to referential ambiguity and semantic incoherence; Figure 3 depicts the results for those subjects only; see Nieuwland and Van Berkum (forthcoming) for individual differences in overall ERP response patterns.

\section{Works Cited}

Almor, A. 1999. Noun-phrase anaphora and focus: the informational load hypothesis. Psychological Review 106.748-65.

Altmann, G., and M. Steedman. 1988. Interaction with context during human sentence processing. Cognition 30.191-238.

Altmann, G. T. M., and Y. Kamide. 1999. Incremental interpretation at verbs: restricting the domain of subsequent reference. Cognition 73.247-64.

Ariel, M. 1990. Accessing noun-phrase antecedents. London, UK: Routledge.

Auer, J. C. P. 1984. Referential problems in conversation. Journal of Pragmatics 8.627-48. 
Bookheimer, S. 2002. Functional MRI of language: new approaches to understanding the cortical organization of semantic processing. Annual Review of Neuroscience 25.151-88.

Brennan, S. E., and H. H. Clark. 1996. Conceptual pacts and lexical choice in conversation. Journal of Experimental Psychology - Learning Memory and Cognition 22.1482-93.

Brown-Schmidt, S., C. Gunlogson, and M. K. Tanenhaus. 2008. Addressees distinguish shared from private information when interpreting questions during interactive conversation. Cognition 107(3).1122-34.

Brown-Schmidt, S., and M. K. Tanenhaus. forthcoming. Real-time investigation of referential domains in unscripted conversation: a targeted language game approach. Cognitive Science.

Brysbaert, M., and D. C. Mitchell. 1996. Modifier attachment in sentence parsing: evidence from Dutch. The Quarterly Journal of Experimental Psychology 49A.664-95.

Caplan, D., and G. S. Waters. 1999. Verbal working memory and sentence comprehension. Behavioral and Brain Sciences 22.77-94.

Chambers, C. G., M. K. Tanenhaus, K. M. Eberhard, H. Filip, and G. N. Carlson. 2002. Circumscribing referential domains during real time language comprehension. Journal of Memory and Language 47.30-49.

Clark, H. H. 1996. Using language. Cambridge, UK: Cambridge University Press.

- 1977. Bridging. Thinking: readings in cognitive science, ed. by P. N. Johnson-Laird and P. C. Wason, 411-420. London, UK/New York, NY: Cambridge University Press.

Clark, H. H., and D. Wilkes-Gibbs. 1986. Referring as a collaborative process. Cognition 22.1-39.

Clark, H. H., and C. J. Sengul. 1979. In search of referents for nouns and pronouns. Memory \& Cognition 7.35-41.

Cooper, R. 1974. The control of eye fixation by the meaning of spoken language. Cognitive Psychology 6.84-107.

Crain, S., and M. Steedman. 1985. On not being led up the garden path: The use of context by the psychological syntax processor. Natural language parsing: Psychological, computational, and theoretical perspectives, ed. by D. Dowty, L. Karttunen and A. Zwicky, 320-58. Cambridge, UK: Cambridge University Press.

Daneman, M., and P. A. Carpenter. 1980. Individual-differences in working memory and reading. Journal of Verbal Learning and Verbal Behavior 19.450-66.

Donnellan, K. 1966. Reference and definite descriptions. Philosophical Review 75.281-304.

Engle, R. W. 2002. Working memory capacity as executive attention. Current Directions in Psychological Science 11.19-23.

Ferreira, F., and C. Clifton, Jr. 1986. The independence of syntactic processing. Journal of Memory and Language 25.348-68.

Ferstl, E. C. 2007. The functional neuronatomy of text comprehension: What's the story so far? Higher Level Language Processes in the Brain: inference and comprehension Processes, ed. by F. Schmalhofer and C. A. Perfetti, 53-102. Mahwah, NJ: Lawrence Erlbaum.

Ferstl, E. C., and F. Th. Siebörger. 2007. Neuroimaging studies of coherence processes. Anaphors in Text: Cognitive, formal and applied approaches to anaphoric reference, (SLCS $=$ Studies in Language Companion Series Vol. 86) ed. by M. Schwarz-Friesel, M. Consten and M. Knees, 225-40. Amsterdam, The Netherlands: Benjamins.

Ferstl, E. C., J. Neumann, C. Bogler, and D. Y. von Cramon. 2008. The extended language network: A meta-analysis of neuroimaging studies on text comprehension. Human Brain Mapping 29.581-93.

Fletcher, P. C., and R. N. A. Henson. 2001. Frontal lobes and human memory - insights from functional neuroimaging. Brain 124.849-81.

Frank, S. L., M. Koppen, L. G. M. Noordman, and W. Vonk. 2007. Coherence-driven resolution of referential ambiguity: a computational model. Memory \& Cognition 35.1307-22.

Frege, G. 1892. On sense and nominatum. The philosophy of language, 2nd edn., reprinted in 1990, ed. by A. P. Martinich, 190-202. New York, NY: Oxford University Press.

Friederici, A. D. 2002. Towards a neural basis of auditory sentence processing. Trends in Cognitive Sciences 6.78-84.

Garnham, A. 1981. Mental models as representations of text. Memory and Cognition 9.560-65.

- 2001. Mental models and the interpretation of anaphora. Philadelphia, PA: Taylor and Francis. 
Garrod, S. C., and A. J. Sanford. 1994. Resolving sentences in a discourse context: how discourse representation affects language understanding. Handbook of psycholinguistics, ed. by Gernsbacher, 675-98. San Diego, CA: Academic Press.

- 1999. Incrementality in discourse understanding. The construction of mental representations during reading, ed. by $H$. van Oostendorp and S. Goldman, 1-27. Mahwah, NJ: Lawrence Erlbaum Associates.

- 1977. Interpreting anaphoric relations: the integration of semantic information while reading. Journal of Verbal Learning and Verbal Behavior 16.77-90.

Garvey, C., and A. Caramazza. 1974. Implicit causality in verbs. Linguistic Inquiry 5.459-64.

Gernsbacher, M. A. 1989. Mechanisms that improve referential access. Cognition 32.99-156.

Gordon, P. C., and R. Hendrick. 1998. The representation and processing of coreference in discourse. Cognitive Science 22.389-424.

Gordon, P. E., R. Hendrick, and K. L. Foster. 2000. Language comprehension and probe list memory. Journal of Experimental Psychology: Learning, Memory, and Cognition 26.766-75.

Graesser, A. C., K. K. Millis, and R. A. Zwaan. 1997. Discourse comprehension. Annual Review of Psychology 48.163-89.

Greene, S. B., G. McKoon, and R. Ratcliff. 1992. Pronoun resolution and discourse models. Journal of Experimental Psychology-Learning Memory and Cognition 18.266-83.

Grosz, B., A. Joshi, and S. Weinstein. 1995. Centering: a framework for modeling the local coherence of discourse. Computational Linguistics 21.203-25.

Grice, H. P. 1975. Logic and conversation. Syntax and Semantics: Volume 3, Speech Acts, ed. by P. Cole and J. Morgan. New York: Academic Press.

Guerry, M., M. Gimenes, D. Caplan, and F. Rigalleau. 2006. How long does it take to find a cause? An online investigation of implicit causality in sentence production. The Quarterly Journal of Experimental Psychology 59.1535-55.

Hagoort, P. 2003. Interplay between syntax and semantics during sentence comprehension: ERP effects of combining syntactic and semantic violations. Journal of Cognitive Neuroscience 15.883-99.

Hanna, J. E., and M. K. Tanenhaus. 2004. Pragmatic effects on reference resolution in a collaborative task: evidence from eye movements. Cognitive Science 28.105-15.

Hanna, J. E., M. K. Tanenhaus, and J. C. Trueswell. 2003. The effects of common ground and perspective on domains of referential interpretation. Journal of Memory and Language 49.43-61.

Harris, T., K. Wexler, and P. J. Holcomb. 2000. An ERP investigation of binding and coreference. Brain \& Language 75.313-46.

Hobbs, J. R. 1979. Coherence and coreference. Cognitive Science 3.67-90.

Huettel, S. A., A. W. Song, and G. McCarthy. 2004. Functional magnetic resonance imaging. Sunderland, MA: Sinauer Associates.

Jackendoff, R. 2002. Foundations of language: brain, meaning, grammar, evolution. Oxford, UK: Oxford University Press.

Jarvikivi, J., R. P. G. van Gompel, J. Hyöna, and R. Bertram. 2005. Ambiguous pronoun resolution - contrasting the first-mention and subject-preference accounts. Psychological Science 16.260-4.

Johnson-Laird, P. N. 1983. Mental models: towards a cognitive science of language, inference, and consciousness. Cambridge, MA: Harvard University Press.

Jung-Beeman, M. 2005. Bilateral brain processes for comprehending natural language. Trends in Cognitive Sciences 9.512-8.

Just, M. A., and P. A. Carpenter. 1992. A capacity theory of comprehension - individual differences in working memory. Psychological Review 99.122-49.

Keysar, B., D. J. Barr, J. A. Balin, and J. S. Brauner. 2000. Taking perspective in conversation: the role of mutual knowledge in comprehension. Psychological Science 11.32-7.

Kintsch, W. 1988. The role of knowledge in discourse comprehension: a construction-integration model. Psychological Review 95.163-82.

- 1998. Comprehension: a paradigm for cognition. New York, NY: Cambridge University Press. 
Klin, C. M., K. M. Weingartner, A. E. Guzmán, and W. H. Levine. 2004. Readers' sensitivity to linguistic cues in narratives: how salience influences anaphor resolution. Memory \& Cognition 32.511-22.

Koornneef, A. W., and J. J. A. Van Berkum. 2006. On the use of verb-based implicit causality in sentence comprehension: evidence from self-paced reading and eye tracking. Journal of Memory and Language 54.445-65.

Kuperberg, G. R., P. J. Holcomb, T. Sitnikova, D. Greve, A. M. Dale, and D. Caplan. 2003. Distinct patterns of neural modulation during the processing of conceptual and syntactic anomalies. Journal of Cognitive Neuroscience 15.272-93.

Kuperberg, G. R., B. M. Lakshmanan, D. N. Caplan, and P. J. Holcomb. 2006. Making sense of discourse: an fMRI study of causal inferencing across sentences. Neuroimage 33.343-61.

Kutas, M. 1997. Presidential address, 1996 - views on how the electrical activity that the brain generates reflects the functions of different language structures. Psychophysiology 34.383-98.

Kutas, M., and S. A. Hillyard. 1980. Reading senseless sentences: Brain potentials reflect semantic incongruity. Science 207(4427).203-205.

Kutas, M., and C. K. Van Petten. 1994. Psycholinguistics electrified: event-related brain potential investigations. Handbook of psycholinguistics, xxii, 1174 pp, ed. by M. A. Gernsbacher, 83-143. San Diego, CA: Academic Press.

Levine, W. H., A. E. Guzmán, and C. M. Klin. 2000. When anaphor resolution fails. Journal of Memory and Language 43.594-617.

Logothetis, N. K., and B. A. Wandell. 2004. Interpreting the BOLD signal. Annual Review of Physiology 66.735-69.

MacDonald, M., and B. MacWhinney. 1990. Measuring inhibition and facilitation in pronouns. Journal of Memory and Language 29.469-92.

MacDonald, M. C., and M. H. Christiansen. 2002. Reassessing working memory: comment on Just and Carpenter (1992) and Waters and Caplan (1996). Psychological Review 109.35-54.

Martinich, A. P. 1990. The philosophy of language, New York, NY: Oxford University Press.

Mason, R. A., and M. A. Just. 2006. Neuroimaging contributions to the understanding of discourse processes. Handbook of Psycholinguistics, 2nd edn., ed. by M. Traxler and M. A. Gernsbacher, 765-99. Amsterdam, The Netherlands: Elsevier.

McKoon, G., and R. Ratcliff. 1980. The Comprehension Processes and Memory Structures Involved in Anaphoric Reference. Journal of Verbal Learning and Verbal Behavior 19.668-82.

McKoon, G., G. Ward, R. Ratcliff, and R. Sproat. 1993. Morphosyntactic and pragmatic factors affecting the accessibility of discourse entities. Journal of Memory and Language 32.56-75.

Montague, R. 1974. Formal philosophy. New Haven, NJ: Yale University Press.

Myers, J. L., and E. J. O’Brien. 1998. Accessing the discourse representation during reading. Discourse Processes 26.131-57.

Nadig, A., and J. Sedivy. 2002. Evidence of perspective-taking constraints in children's on-line reference resolution. Psychological Science 13.329-36.

Ni, W., R. T. Constable, W. E. Mencl, K. R. Pugh, R. K. Fulbright, S. E. Shaywitz, B. A. Shaywitz, J. C. Gore, and D. Shankweiler. 2000. An event-related neuroimaging study distinguishing form and content in sentence processing. Journal of Cognitive Neuroscience 12.120-33.

Nieuwland, M. S., and J. J. A. Van Berkum. 2006. Individual differences and contextual bias in pronoun resolution: Evidence from ERPs. Brain Research 1118.155-67.

- forthcoming. The interplay between semantic and referential aspects of anaphoric noun phrase resolution: evidence from ERPs. Brain and Language.

Nieuwland, M. S., M. Otten, and J. J. A. Van Berkum. 2007a. Who are you talking about? Tracking discourse-level referential processing with event-related brain potentials. Journal of Cognitive Neuroscience 19.228-36.

Nieuwland, M. S., K. M. Petersson, and J. J. A. Van Berkum. 2007b. On sense and reference: examining the functional neuroanatomy of referential processing. Neuroimage 37.993-1004.

Novick, J. M., J. C. Trueswell, and S. L. Thompson-Schill. 2005. Cognitive control and parsing: reexamining the role of Broca's area in sentence comprehension. Cognitive Affective \& Behavioral Neuroscience 5.263-81. 
O'Doherty, J. P., A. Hampton, and H. Kim. 2007. Model-based fMRI and its application to reward learning and decision making. Annals of the New York Academy of Sciences 1104.35-53.

Osterhout, L. 1997. On the brain response to syntactic anomalies: Manipulations of word position and word class reveal individual differences. Brain and Language 59.494-522.

Osterhout, L., and P. J. Holcomb. 1992. Event-related brain potentials elicited by syntactic anomaly. Journal of Memory and Language 31.785-806.

Osterhout, L., and L. A. Mobley. 1995. Event-related brain potentials elicited by failure to agree. Journal of Memory and Language 34.739-73.

Osterhout, L., P. J. Holcomb, and D. A. Swinney. 1994. Brain potentials elicited by garden-path sentences: evidence of the application of verb information during parsing. Journal of Experimental Psychology: Learning, Memory \& Cognition 20.786-803.

Partee, B. 1987. Noun phrase interpretation and type-shifting principles. Studies in discourse representation theory and the theory of generalized quantifiers, ed. by J. Groenendijk, D. de Jongh, and M. Stokhof, 115-44. Dordrecht, The Netherlands: Reidel.

Rayner, K., M. Carlson, and L. Frazier. 1983. The interaction of syntax and semantics during sentence processing: eye movements in the analysis of semantically biased sentences. Journal of Verbal Learning and Verbal Behavior 22.358-74.

Reichle, E. D., and R. A. Mason. 2007. The neural signatures of causal inferences: A preliminary computational account of brain-imaging and behavioral data. Higher level language processes in the brain: Inference and comprehension processes, ed. by F. Schmalhofer and C. A. Perfetti, 211-32. Mahwah, NJ: Lawrence Erlbaum.

Rigalleau, F., D. Caplan, and V. Baudiffier. 2004. New arguments in favour of an automatic gender pronominal process. The Quarterly Journal of Experimental Psychology A 57.893-933.

Rugg, M. D. and M. G. H. Coles. 1997. Electrophysiology of mind, Vol 25. Oxford, UK: Oxford University Press.

Sanford, A. J., and S. C. Garrod. 1989. What, when, and how? Questions of immediacy in anaphoric reference resolution. Language and Cognitive Processes 4.SI235-62.

Sedivy, J. 2002. Invoking discourse-based contrast sets and resolving syntactic ambiguities. Journal of Memory and Language 341-70.

- 2003. Pragmatic versus form-based accounts of referential contrast: evidence for effects of informativity expectations. Journal of Psycholinguistic Research 21.3-23.

Sedivy, J. C., M. K. Tanenhaus, C. G. Chambers, and G. N. Carlson. 1999. Achieving incremental semantic interpretation through contextual representation. Cognition 71.109-48.

Spivey-Knowlton, M., and M. K. Tanenhaus. 1994. Referential context and syntactic ambiguity resolution. Perspectives on sentence processing, ed. by C. Clifton, L. Frazier and K. Rayner, 415-39. Hillsdale, NJ: Lawrence Erlbaum Associates.

Spivey, M. J., M. K. Tanenhaus, K. M. Eberhard, and J. C. Sedivy. 2002. Eye-movements and spoken language comprehension: Effects of visual context on syntactic ambiguity resolution. Cognitive Psychology 45.447-81.

Stewart, A. J., J. Holler, and E. Kidd. 2007. Shallow processing of ambiguous pronouns: evidence for delay. The Quarterly Journal of Experimental Psychology 60.1680-96.

Swaab, T. Y., C. C. Camblin, and P. C. Gordon. 2004. Electrophysiological evidence for reversed lexical repetition effects in language processing. Journal of Cognitive Neuroscience $16.715-26$.

Tanenhaus, M. K., M. J. Spivey-Knowlton, K. M. Eberhard, and J. C. Sedivy. 1995. Integration of visual and linguistic information in spoken language comprehension. Science 268.1632-4.

Trueswell, J. C., and M. K. Tanenhaus. 2005. Approaches to studying world-situated language use: bridging the language-as-product and language-as-action traditions. Cambridge, MA: MIT Press.

Van Berkum, J. J. A. 2004. Sentence comprehension in a wider discourse: can we use ERPs to keep track of things? The on-line study of sentence comprehension: eyetracking, ERPs and beyond, ed. by M. Carreiras and C. Clifton, Jr, 229-70. New York, NY: Psychology Press.

Van Berkum, J. J. A., C. M. Brown, and P. Hagoort. 1999. Early referential context effects in sentence processing: Evidence from event-related brain potentials. Journal of Memory and Language 41.147-82. 
Van Berkum, J. J. A., C. M. Brown, P. Hagoort, and P. Zwitserlood. 2003. Event-related brain potentials reflect discourse-referential ambiguity in spoken language comprehension. Psychophysiology 40.235-48.

Van Berkum, J. J. A., P. Zwitserlood, M. C. M. Bastiaansen, C. M. Brown, and P. Hagoort. 2004. So who's 'he' anyway? Differential ERP and ERSP effects of referential success, ambiguity and failure during spoken language comprehension. Annual meeting of the Cognitive Neuroscience Society (CNS-2004), San Francisco, April 18-20.

Van Berkum, J. J. A., A. W. Koornneef, M. Otten, and M. S. Neuwland. 2007. Establishing reference in language comprehension: an electrophysiological perspective. Brain Research 1146.158-71.

Wagner, A. D., B. J. Shannon, I. Kahn, and R. L. Buckner. 2005. Parietal lobe contributions to episodic memory retrieval. Trends in Cognitive Sciences 9.445-53.

Zwaan, R. A., and G. A. Radvansky. 1998. Situation models in language comprehension and memory. Psychological Bulletin 123.162-85.

Zysset, S., O. Huber, A. Samson, E. C. Ferstl, and D. Y. von Cramon. 2003. Functional specialization within the anterior medial prefrontal cortex: a functional magnetic resonance imaging study with human subjects. Neuroscience Letters 335.183-6. 